\title{
PLAGIARISM IN CREATING ACADEMIC \\ BASED ARGUMENTATIVE ESSAY: THE STRATEGIES TO AVOID IT
}

\author{
Anak Agung Putri Maharani \\ English Language Education Study Program, \\ Mahasaraswati Denpasar University, Denpasar, Indonesia \\ agungputrimaharani@gmail.com
}

\begin{abstract}
Through this paper, the strategies of avoiding plagiarism implemented by the participants were presented. There were 136 fifth semester students of English Language Education Study Program (hereafter, ELESP) in Mahasaraswati Denpasar University who willingly contributed to the research investigation. All of them enrolled the Writing IV course which mainly focuses on academic writing and plagiarism. To attain the data, an open-ended questionnaire was distributed which followed by interview and Focus Group Discussion (henceforward, FGD). The obtained data were analyzed by means of Interactive Model which involves data collection, data filter, data presentation, and verification. It was found that the students encompassed 4 strategies in the attempt to avoid plagiarism such as producing a thorough outline prior to drafting, using own words, citing: quoting, paraphrasing, and utilizing plagiarism checker. These strategies are categorized into 3 different divisions based on the period of applying them.
\end{abstract}

\section{INTRODUCTION}

Academic writing in higher education does matter as students are challenged by the $21^{\text {st }}$ century education. Academic writing is necessary for university students especially for those who deal with various assignments. As stated by Ofte (2014) that academic writing plays a major role in higher education. Oshima and Hogue (2007) stated that academic writing is packaged by a formal set of structures in conveying ideas and it obviously respects formality. It has its own rules and practices which are strictly required to be followed which differentiate it with personal and creative writing. Freebody and Chambers (2017) stated that achieving the success of academic writing engrosses many elements that contribute to it which range from students' willingness to do the planning, researching, reading, critical thinking and understanding the question as well as structuring the assignment into a coherent piece of 
analytical work that adequately answers the question.

Actually, university students in Indonesia are non-native English speakers who assume that academic writing is significant to master. Moreover, students entering higher education are expected to become proficient academic writers in the course of their studies. It is because academic writing is used to express acquired knowledge in specific area (Ofte, 2014). This genre of writing tends to be serious in nature and often demonstrates particular theories or arguments. Moreover, Howard stated that academic writing is "not a reflex of morality or property but a complex intellectual skill"' (2004a, p. 9).

Actually, one of essay which belongs to English academic writing is argumentative essay. Argumentative writing as a mode of academic writing constitutes an important part of foreign language learners' academic experience. Based on Baker, Brizee, and Angeli (2013), writing an English academic argumentative essay includes a thesis statement in the introduction, followed by paragraphs that start with topic sentences, and examples that support the thesis, which are then followed by a logical conclusion. Lastly, students are taught how to support their arguments by using correct referencing conventions.
But, the rapid growth of millennial era which provides unlimited accessible information for students has led them to plagiarize as they get help easily in completing assignment and so on. Information needed is obtained from varied sources that can be accessed anytime anywhere. It increases the opportunity of plagiarizing if they neglect the academic integrity. Students are expected to uphold the core values of academic integrity which include honesty, trust, fairness, respect, and responsibility wherein these core values, combined with finding one's purpose and passion and applying them in and out of classroom learning, produce students who become extraordinary citizens (Wisconsin, 2018).

Bailey (2006, p. 7) stated that, "Plagiarism means taking information or ideas from another writer and using them in your own work, without acknowledging the source in an accepted manner'. However, it can be done intentionally or unintentionally, dependable on the case that the students do. Intentional plagiarism involves including the words and ideas of others in own work that neglected to cite. It means that appreciation towards writing made by authors by giving credits or putting sources is necessary. Definitely, writers may borrow 
someone's works to support their works, but citing is significantly required. Conversely, unintentional plagiarism may involve careless paraphrasing, poor documentation, quoting excessively and failure to use own voice. Plagiarism has a tight relationship with argumentative essay as the writers need to support their writing by various reasonable reasons and evidences which taken from enormous sources.

Several reasons of doing plagiarism are identified due to lack understanding of plagiarism amongst students. As listed in Yang and Lin (2009), the following are the reasons for plagiarism such as, the pressure to obtain good grades, time management issues, language difficulties, cultural differences (with respect to pedagogic and writing practice), attitude/belief that cheating is acceptable and inattention to citation practices. Due to many reasons of doing this act, writers require to apply the strategies to avoid it.

Devlin (n.d.), in brief, stated that plagiarism can be avoided through starting early, working hard, referencing your work, being careful and being fair. University education is challenging. As the consequence, university students are expected to work hard and put extra effort and time into study. It is important at the start of each assignment to spend some time reading and considering the assessment requirements. Additionally, comprehending and educating self about plagiarism is important as well.

Based on the elucidation above, this study comprises a research question which is formulated as follows: What are the strategies used by the students to avoid plagiarism in creating an academic-based argumentative essay?

\section{RESEARCH METHODS}

This research made use of descriptive qualitative study which involved the fifth semester students who had enrolled in Writing IV course in English Language Education Study Program, Faculty of Teacher Training and Education, Mahasaraswati Denpasar University. There were 136 respondents who were willingly to participate as the source of data.

Actually, to obtain a rich set of data, the researcher distributed openended questionnaire and conducted interview and Focus Group Discussion (hereafter, FGD). The questionnaire with was administered to attain the indicators from the wider group of students (the researcher distributed it to 136 students). However, the interview and FGD were targeted at a small group of students who were regarded as the 
representative of the whole participants.

Further, to support the questionnaire data, 15 interviewees were invited to join the individual interview and FGD. They were chosen because they were interested in further follow up. The interview and FGD results were tape recorded, transcribed and analyzed.

The yielded data from spreading the questionnaire as well as conducting interview and FGD were analysed by means of Interactive Model which involves data collection, data filter, data presentation, and verification. Then the analysis result was translated into tables to facilitate the interpretation.

\section{FINDING AND DISCUSSION}

There were three research instruments designed and administered to obtain the required data, such as, open-ended questionnaire, two interview guides for individual interview and FGD session. They were used to ensure that the investigated phenomenon was well comprehended and scrutinized from threefold point of views because capturing the pictures of a single phenomenon from different angles will allow for a reliable level of accuracy.

The obtained data by means of administering

open-ended questionnaire, interview and FGD were filtered which followed by summing them up in the following table:

\begin{tabular}{|c|c|c|}
\hline \multirow{2}{*}{$\begin{array}{l}\text { No. } \\
1\end{array}$} & \multicolumn{2}{|r|}{ Strategies } \\
\hline & Pre-activity & a. Producing a thorough outline prior to drafting \\
\hline \multirow{2}{*}{2} & \multirow{2}{*}{ Whilst-activity } & a. Using own words \\
\hline & & b. Citing: Quoting, Paraphrasing \\
\hline 3 & Post-activity & a. Utilizing plagiarism checker \\
\hline
\end{tabular}

Table 1. The Strategies of Avoiding Plagiarism

Based on the table, it can be pointed out that the respondents reported various strategies in avoiding plagiarism which can be divided into three cohorts: preactivity, whilst activity, and postactivity. In each activity, the respondents reveal different strategies which show their attempt in preventing plagiarism.

In the pre-activity, it is addressed that creating a thorough outline assists the respondents to avoid plagiarism. Rather than being inspired from and copying someone's ideas, making an essay which is based on own idea is prominent to diligently keep track of where the ideas come from. Most of the respondents said that outlining is the first step in preventing plagiarism. Argumentative essay is straightforward in its organization. In this type of essay, the writers need to list the claim, reasons, evidences of their argument and refutation. As stated by Battaglia (2018), an argumentative essay writer is just like 
a lawyer who must present the issue at hand, give background, and put forth the main argument -- all in a logical, intellectual and persuasive way. Thus, outlining helps them in developing their ideas and finding relevant sources to support their writing.

Writing an outline that clearly formulates an argument will help establishing the boundaries between own ideas and those of the sources (Turnitin, n.d.). The respondents stated that using other sources of information needs planning on how to include them in the paper. It means working out a balance between the ideas taken from other sources and own original ideas. It is crucial to begin developing outline early in the essay writing process. An outline shows the framework of an essay; therefore, it is well known as a "skeleton" of the essay. The outline may probably change as the writers read, learn and take notes, but it will be there to keep them pondering about where what they read will fit into the essay.

Next, the whilst-activity which covers drafting argumentative essay. Having created the outline prior to drafting, the respondents were led to write. The respondents reported two strategies while drafting their essay in preventing themselves from plagiarizing. First, using own words.
In making the essay, the respondents said that they developed the outline by using their own words into rough draft. Definitely, the respondents utilized online or offline dictionary in increasing their vocabulary storage and modifying the sentences they made. It is done to keep in using own words. "By writing in one's own words, students can build the right habits to protect their future careers, reputations, and self-respect" (Mitchell, 2014).

Besides, the respondents did the second strategy - doing citation. They cited information from other sources by quoting and paraphrasing. It is dependable on the closeness of the writings to the source of writings. Much of the work students produce at university will involve the important ideas, writings and discoveries of experts in the field of study (UNSW, 2017). Besides, it frequently happens when writers need to support their argument, highlight important points of their writing, or increase the credibility of their paper. To do so, writers may incorporate another writers' work into theirs carefully. It supports the respondents' opinion that both quoting and paraphrasing are important tools for reshaping information to suit many varied university writing assignments.

However, quoting and paraphrasing are different in many 
ways. The respondents stated that quoting is done when they use identical words to the original source which must be attributed to the original author. On the other hand, the respondents pointed out that paraphrasing is done when they use the ideas of others by using their own words without changing the meaning of the original ideas. Similarly, the respondents added that a paraphrase must also be attributed to the original source. Both quoting and paraphrasing are used to appreciate others' works and give credits.

Lastly, post-activity is related to the last strategy done by the respondents after finishing their essay. In post-activity, the respondents are fond of utilizing online application, well-known as plagiarism checker that available through assessing the internet. There are various free applications to check written work whether plagiarism is identified or not. Calvano (2012) stated that "Plagiarism checker is suitable for those who are serious about their academic work". The respondents argued that plagiarism checker is accessible and it is an effective tool to identify the plagiarized materials.

Plagiarism checker helps struggling writers in various ways. The respondents stated that plagiarism checker highlights the content that is exact. It means that they can see what words are exactly the same with the original one. Directly, they can fix it before publishing their final essay to be scored. Moreover, this software also gives percentages of similarity. The respondents must have low percentages of similarity for their essay to be regarded free from plagiarizing because the bigger the percentage is, the lesser academic integrity the essay has.

To sum up, there are 4 main strategies applied by the respondents in avoiding plagiarism. The 4 strategies happen in different writing activity.

\section{CONCLUSION}

Based on the finding and discussion, it was found that there are 4 strategies implemented by the students to avoid plagiarism in creating English academic argumentative essay. There are producing a thorough outline prior to drafting, using own words, citing: quoting, paraphrasing, and utilizing plagiarism checker. The strategies are categorized into 3 different groups based on the period of applying the strategies. 


\section{REFERENCES}

Baker, J, Brizee, A, \& Angeli, E. (2013). Argumentat8ive Essay. Retrieved $11^{\text {th }}$ of February 2018 from

https://owl.english.purdue.edu/ owl/resource/685/05/

Bailey, S. (2006). Academic Writing: A Handbook for International Students (2nd Ed.). London: Routledge.

Battaglia, S. (2018). How to Write a Good Argumentative Essay Introduction. Retrieved $12^{\text {th }}$ of February 2018 from http://education.seattlepi.com/w rite-good-argumentative-essayintroduction-1484.html.

Calvano, B. (2012). 5 Reasons to Use a Plagiarism Checker. Retrieved $14^{\text {th }}$ of February 2018 from http://en.writecheck.com/blog/2 012/07/26/5-reasons-to-use-aplagiarism-checker.

Devlin. (n.d.) Avoiding plagiarism and cheating: A guide for students at Swinburne University of Technology. Australia: Swinburne University of Technology.

Freebody \& Chambers. (2017). Academic Writing. Retrieved $1^{\text {st }}$ of September 2017 from http://sydney.edu.au/education social work/learning teaching Lstudents/first year experience/ academic writing.shtml.
Howard, R.M. (2004a). Culture and academic discourse: Cultivating authority in language and text. Texas $\mathrm{A}$ and $\mathrm{M}$ University. Retrieved $11^{\text {th }}$ of February 2018 from

http://wrt.howard.syr.edu/Pape rs/TAMU.htm

Mitchell, S. (2014). 6 Reasons to Write in Your Own Words. Retrieved $14^{\text {th }}$ of February 2018 from http://en.writecheck.com/6reasons-to-write-in-your-ownwords/

Ofte. (2014). Learning to write: Writing to Le arn Academic Writing: A Literature Review . Retrieved $12^{\text {th }}$ of February 2018 from

http://new.learnhigher.ac.uk/res ources/files/academic writing li terature.pdf

Oshima, A \& H, A. (2007). Introduction to Academic Writing ( $3^{\text {rd }}$ Ed.). New York: Pearson Education. Turnitin. (2017). Preventing Plagiarism when Writing. Retrieved $12^{\text {th }}$ of February 2018 from http://www.plagiarism.org/article /preventing-plagiarism-whenwriting.

UNSW. (2017). Paraphrasing, Summarising and Quoting. Retrieved $14^{\text {th }}$ of February 2018 from

https://student.unsw.edu.au/par 
aphrasing-summarising-and-quoting Wisconsin. (2018.) Academic Intergirty. Retrieved $12^{\text {th }}$ of February 2018 from https://conduct.students.wisc.ed $\mathrm{u} /$ academic-integrity/

Yang, M \& Lin, S. (2009). The perception of referencing and plagiarism amongst students coming from Confucian heritage cultures. A Paper presented at the $4^{\text {th }}$ Asia Pacific Conference on Educational Integrity (4APCEI) 28-30 September 2009, University of Wollongong NSW Australia. 